\title{
Medievalista
}

Online

$29 \mid 2021$

Número 29

\section{Webinar "La sociedad política de las ciudades de la Península Ibérica. Oficios, movilidad social y relaciones de poder"}

Webinar "The political society of cities in the Iberian Peninsula. Crafts, social mobility and power relations"

\section{Enrique José Ruiz Pilares}

\section{OpenEdition}

\section{Journals}

\section{Edición electrónica}

URL: https://journals.openedition.org/medievalista/3998

DOI: 10.4000/medievalista.3998

ISSN: 1646-740X

Editor

Instituto de Estudos Medievais - FCSH-UNL

\section{Edición impresa}

Paginación: 403-410

\section{Referencia electrónica}

Enrique José Ruiz Pilares, «Webinar "La sociedad política de las ciudades de la Península Ibérica. Oficios, movilidad social y relaciones de poder"», Medievalista [En línea], 29 | 2021, Publicado el 01 enero 2021, consultado el 12 junio 2021. URL: http://journals.openedition.org/medievalista/3998 ; DOI: https://doi.org/10.4000/medievalista.3998

Este documento fue generado automáticamente el 12 junio 2021.

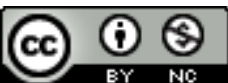

Mediavalista está licenciado com uma Licença Creative Commons - Atribuição-NãoComercial 4.0 Internacional. 
Webinar "La sociedad política de las ciudades de la Península Ibérica. oficios, movilidad social y relaciones de poder"

Webinar "The political society of cities in the Iberian Peninsula. Crafts, social mobility and power relations"

Enrique José Ruiz Pilares

NOTA DEL EDITOR

Data recepção do artigo / Received for publication: 18 de Setembro de 2020 


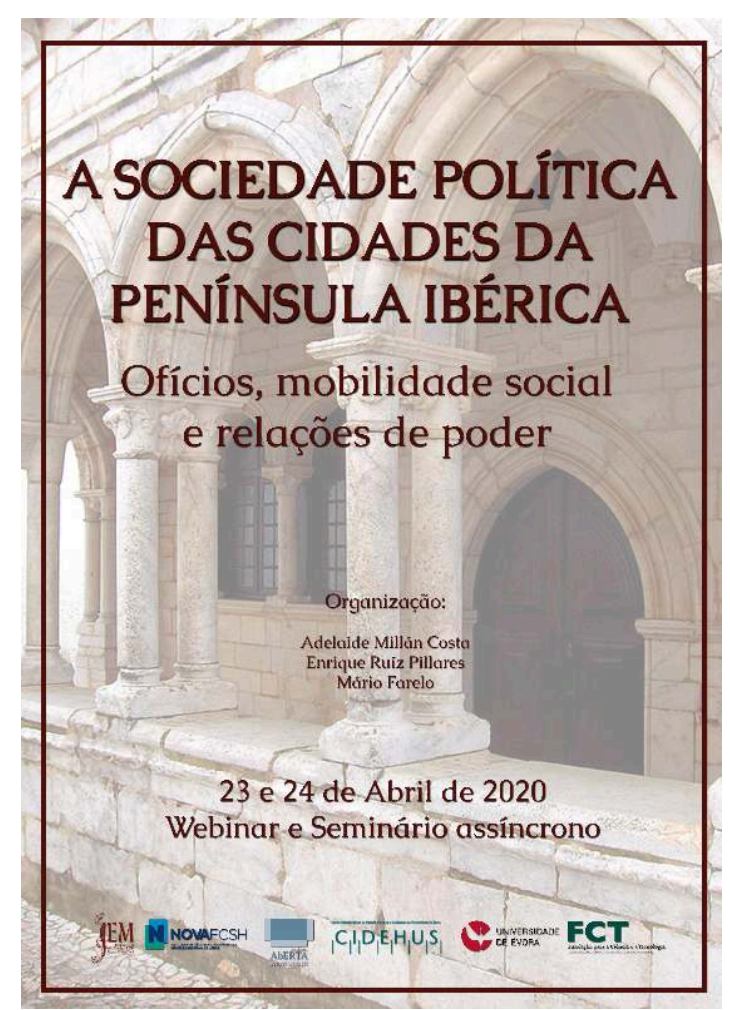

Fig. 1 - Cartel de divulgación del Webinar "A sociedade política das cidades da Península Ibérica. Ofícios, mobilidade social e relações de poder"

(C) Instituto de Estudos Medievais - NOVA FCSH

1 Este encuentro, que fue organizado y proyectado por sus coordinadores como una actividad presencial, se convirtió en una actividad virtual debido a la grave pandemia de COVID y al cierre de fronteras que se ha vivido en la primavera de 2020. A pesar de las vicisitudes y todos los problemas acontecidos, se apostó por mantener el esfuerzo de meses de trabajo de coordinadores e investigadores y difundirlo de manera gratuita a todas aquellas personas interesadas que se conectaron desde sus hogares a través de la versión virtual del seminario.

2 Finalmente, los días 23 y 24 de abril de 2020 - los mismos días escogidos para el encuentro presencial, y a través de la plataforma virtual de la Universidade Aberta (UAb) - pudo llevarse a cabo el seminario. La organización del encuentro recayó en el Instituto de Estudos Medievais (IEM) de la Universidade Nova de Lisboa (NOVA FCSH) y el Centro Interdisciplinar de Historia, Culturas y Sociedades de la Universidad de Évora (CIDEHUS), con el apoyo logístico mencionado de la UAb. El encuentro fue coordinado por los profesores Adelaide Costa (UAb), Mário Farelo (NOVA FCSH) y Enrique Ruiz Pilares de la Universidad de Cádiz (UCA), todos miembros del IEM. Este webinar se ha insertado dentro de las actividades científicas formativas del doctorado en estudios medievales de las instituciones participantes (NOVA FCSH; UAb).

En el Webinar Internacional participaron un grupo de 15 investigadores de diferentes Universidades e Institutos de investigación de España y Portugal, que contaban con una trayectoria investigadora centrada en el estudio del mundo urbano en los diferentes reinos cristianos que constituyeron la Península Ibérica a finales de la Edad Media (Portugal, Castilla, Aragón y Navarra). El interés principal del webinar era generar un debate partiendo de la fructífera historiografía peninsular en estas cuestiones que se 
había llevado a cabo en los últimos años ofreciendo una visión pan-ibérica comparativa que superase las fronteras regionales y nacionales. Las diferentes aportaciones de los investigadores giraron a partir de cinco ejes temáticos propuestos por los coordinadores: la tipología de los oficios municipales, los mecanismos de selección, la procedencia social, los procesos de ascenso social y las relaciones de poder entre los diferentes componentes de la sociedad política.

Durante el primer día, organizado en dos amplias sesiones (Diversidad Geopolítica y Diversidad Jurisdiccional), los diferentes investigadores presentaron síntesis de la problemática y estados de la cuestión de las diferentes sociedades políticas urbanas de la Península Ibérica, aportando síntesis y reflexiones a partir de sus propias investigaciones.

5 En la primera parte del encuentro participaron aquellos investigadores cuya investigación se ha centrado en el reino de Castilla. Para la cornisa cantábrica, María Álvarez Fernández (Universidad de Vigo), tomando como observatorio principal de estudio el caso de Asturias, nos habló de la solidez de los sistemas tradicionales de elección de los oficiales, vigentes a finales del siglo XV, basados en la elección urbana y popular de sus representantes, frente a las injerencias de la nobleza local. Sistema que tuvo una mayor vigencia en los territorios asturianos que en otros espacios de la zonavillas cántabras y vascas. No obstante, a partir del gobierno de los Reyes Católicos se inicia un proceso de reforma y uniformidad de los sistemas de elección que afectaron a todo el norte peninsular. En el caso de la meseta castellana, el profesor José Antonio Jara Fuente (Universidad de Castilla-La Mancha), nos aportó una visión de conjunto sobre las consecuencias de la instauración del concejo cerrado o regimiento como sistema de gobierno en el siglo XIV. La reducción de los puestos con capacidad de decisión política en el seno de la asamblea concejil no hizo más que consolidar un proceso de reducción del poder en una serie de linajes, especialmente de origen hidalgo. Una realidad que no significó que no existiesen recursos y mecanismos de poder al alcance de otras familias y colectivos de caballeros y pecheros, uno de los temas más debatidos a lo largo de este webinar. De norte a sur, llegando a Andalucía, el autor de esta reseña presentó una visión de conjunto sobre la formación del grupo dirigente de las ciudades y villas andaluzas desde la conquista castellana del territorio en el siglo XIII. Una élite caballeresca que domino todas las instancias del poder urbano, aunque litigando constantemente contra las injerencias de la monarquía, la nobleza señorial, que quiso reducir la influencia de las familias dirigentes urbanas. El margen de ascenso social para otros grupos sociales fue reducido, pero tanto artesanos como mercaderes encontraron ciertos espacios de poder, especialmente en el control del mercado y las finanzas.

6 La realidad analizada para el caso castellano tenía muchas similitudes en el caso del reino de Navarra, estudiado por Alicia Montero Málaga (Universidad Autónoma de Madrid). A través del análisis comparado de los regímenes municipales de las principales ciudades y villas del reino - Olite, Estella, Tudela y Pamplona -, ha podido constatar el proceso de cierre y elitización del grupo dirigente y también las similitudes existentes con el modelo francés de buenas villas (bonne ville), con los que el reino navarro estuvo muy vinculado durante el periodo medieval. Los estudios sobre la corona de Aragón fueron presentados por el profesor Juan Antonio Barrio Barrio. A pesar de la dificultad de analizar una realidad compleja y diversa -compuestos por cuatro espacios políticos diferenciados - nos sintetizó las peculiaridades de los 
gobiernos del territorio aragonés, que son los que mantuvieron menos similitudes con los sistemas concejiles del resto de reinos la Península Ibérica. Para ello procedió al análisis de los sistemas electorales y de los perfiles sociales de sus grupos dirigentes, con un peso de familias procedentes de sectores comerciales y artesanales, además de mayores posibilidades de renovación y acceso político del que hemos observado para otros espacios, especialmente Castilla.

7 Finalmente, el reino de Portugal fue presentado por Joaquim Serra, que nos aproximó al sistema concejil portugués a través del ejemplo de Évora. Como ya se ha señalado para el resto de los espacios peninsulares, la oligarquización del gobierno urbano en un reducido número de familias es una constante en la historia municipal ibérica. Un grupo dirigente mucho más heterogéneo en su composición social que en Castilla, con un mayor peso de familias procedentes de ambientes comerciales, asimilándose mucho más al caso aragonés.

8 Tras la visión general presentada en la primera sesión, la segunda, dedicada a la diversidad jurisdiccional se centró en problemáticas como las diferencias entre el señorío nobiliario y el realengo, o la organización municipal de las ciudades bajo el control de las órdenes militares. La problemática analizada por Manuela Santos Silva (Universidade de Lisboa) fueron los concejos portugueses bajo jurisdicción de reinas consortes o reinas madres. En estos territorios existía en ocasiones problemáticas jurisdiccionales debido a las diferentes obediencias de muchos oficiales, entre el monarca y las gobernantes legítimas de estos territorios, siendo los más perjudicados los poderes concejiles, quienes vieron limitados su margen de actuación frente a los poderes superiores.

9 Centrado en el caso castellano, Víctor Muñóz Gómez (Universidad de La Laguna), nos aproximó a la realidad de los pequeños señoríos castellanos, especialmente en el área riojana y Extremadura. Más allá de confirmar los mismos procesos de oligarquización y elitización de los gobiernos urbanos como una dinámica constante a finales de la Edad Media, fue bastante sugestiva su síntesis sobre las redes tejidas por los diferentes señores dentro de los gobiernos urbanos de las villas bajo su dominio. La consolidación del grupo dirigente no puede desentenderse del poder señorial que en muchas ocasiones promocionaba a sus más fieles servidores con prebendas y oficios, tantos concejiles como en el seno de la administración señorial, que, por otra parte, le aseguraban el control de sus dominios. Una realidad similar, pero para el caso portugués, ha constatado Ana Cláudia Silveira (NOVA FCSH). Esta investigadora nos habló de los gobiernos urbanos en los territorios bajo el señorío de las órdenes militares portuguesas, tratando aspectos interesantes como las relaciones familiares entre los caballeros de las órdenes y la élite dirigente, especialmente a partir del caso de Setúbal en el siglo XV, que pertenecía a la orden de Santiago. En este trabajo se pudo constatar la influencia de los administradores y comendadores de la orden en el gobierno de esta próspera villa comercial.

10 En último lugar, Raquel de Oliveira Martins (Universidade do Minho) nos sumergió en la realidad política de Braga, una ciudad con una singularidad que le ha permitido servir de observatorio para un estudio comparativo sobre las diferencias entre los sistemas de elección entre el señorío y el realengo -la ciudad estuvo bajo el control regio entre 1402 y 1472 . El elemento común, sin duda, y como se ha podido constatar en este webinar. fueron los procesos de patrimonialización de los oficios y consolidación 
de un grupo dirigente que va más allá de las barreras jurisdiccionales de pertenencia de la ciudad.

11 Durante las dos sesiones, un panel de comentadores, formado por los profesores Herminia Vasconcelos Vilar, Arnaldo Melo, Adelaide Millán da Costa y Mário Farelo, y encabezado por la profesora Maria Helena da Cruz Coelho, se encargó de preguntar, debatir y comentarle a los diferentes investigadores aquellos aspectos más interesantes y aquellos que deberían de profundizarse en una publicación posterior.

El día 24 de abril, segundo día de la sesión, se centró en un seminario asíncrono donde todos los inscritos en el webinar realizaron múltiples preguntas a los diferentes investigadores del encuentro. Este modelo de debate fue muy ágil y enriquecedor y permitió profundizar en muchas de las cuestiones en las que no pudo incidirse por falta de tiempo y por la visión general que quiso imprimir cada investigador en el día anterior. Esta actividad reflejó que el encuentro fue mucho más allá de la mera sustitución de una actividad presencial por la virtual, sino que permitió introducir una novedosa metodología y estructura al programa que fue muy beneficiosa para dinamizar el diálogo científico y atender mejor las inquietudes de los asistentes al webinar. Los coordinadores creemos que en el futuro podrían utilizarse un sistema mixto de diálogo directo y asíncrono para fortalecer los resultados de los encuentros científicos.

El balance final del encuentro ha sido muy interesante y prometedor, a pesar de las vicisitudes que todos conocemos y hemos vivido en la primavera de 2020. Las ponencias presentadas, enriquecidas con las aportaciones de los diferentes investigadores y las inquietudes de los participantes en el seminario asíncrono serán publicadas en las próximas fechas para que el paso del tiempo no diluya un encuentro tan satisfactorio tanto a nivel académico como personal.

\section{AUTOR}

\section{ENRIQUE JOSÉ RUIZ PILARES}

Universidad de Cádiz, Departamento de Historia, Geografía y Filosofía. Calle Gómez Ulla s/n Cádiz, España. enrique.pilares@uca.es. https://orcid.org/0000-0002-8624-0667 